\title{
Robotic adrenalectomy: evaluation of cost-effectiveness
}

\author{
Carmela De Crea ${ }^{1,2}$, Giovanni Arcuri ${ }^{3}$, Francesco Pennestrì ${ }^{2}$, Chiara Paolantonio ${ }^{2}$, \\ Rocco Bellantone ${ }^{1,2}$, Marco Raffaelli ${ }^{1,2}$
}

${ }^{1}$ Dipartimento Universitario di Medicina e Chirurgia Traslazionale, Università Cattolica del Sacro Cuore, Rome, Italy; ${ }^{2}$ UOC Chirurgia Endocrina e Metabolica, Fondazione Policlinico Universitario A. Gemelli IRCCS, Roma - Università Cattolica del Sacro Cuore, Roma, Italy; ${ }^{3}$ UOC Tecnologie Sanitarie, Fondazione Policlinico Universitario A. Gemelli IRCCS, Roma, Italy

Contributions: (I) Conception and design: C De Crea, G Arcuri, R Bellantone, M Raffaelli; (II) Administrative support: G Arcuri; (III) Provision of study materials or patients: C De Crea, G Arcuri, F Pennestrì, C Paolantonio; (IV) Collection and assembly of data: G Arcuri, F Pennestrì, C Paolantonio; (V) Data analysis and interpretation: C De Crea, G Arcuri, R Bellantone, M Raffaelli; (VI) Manuscript writing: All authors; (VII) Final approval of manuscript: All authors.

Correspondence to: Marco Raffaelli. Dipartimento Universitario di Medicina e Chirurgia Traslazionale, U.O.C. Chirurgia Endocrina e Metabolica, Fondazione Policlinico Universitario A. Gemelli IRCCS, Roma, Università Cattolica del Sacro Cuore, L.go A. Gemelli 8, 00168, Rome, Italy. Email: marco.raffaelli@unicatt.it.

\begin{abstract}
Laparoscopic adrenalectomy (LA) is the preferred treatment option for adrenal lesions, considering the improved patients outcomes, due to the reduced postoperative morbidity and postoperative pain, the faster recovery and the shorter length of hospital stay. The widespread diffusion of robotic technology led to the development and standardization of robot-assisted approach to adrenalectomy. However, to date, no clear benefit from the use of the robot-assisted approach has been found. The higher costs remain an important drawback and limit the implementation of robot-assisted adrenalectomy (RA) programs. This review summarizes the current available data regarding RA including its operative outcomes, advantages and drawbacks in comparison with conventional LA, evaluating its cost-effectiveness.
\end{abstract}

Keywords: Robotic adrenalectomy; minimally invasive adrenalectomy; adrenal tumours; cost-effectiveness; personalized medicine

Submitted Feb 21, 2020. Accepted for publication Mar 31, 2020.

doi: $10.21037 /$ gs.2020.03.44

View this article at: http://dx.doi.org/10.21037/gs.2020.03.44

\section{Introduction}

Adrenalectomy is a technically demanding procedure which requires careful and meticulous dissection around major vessels and organs in a relatively narrow space as retroperitoneum is.

Laparoscopic adrenalectomy (LA) has become the preferred treatment option for adrenal lesions since first being performed in 1992 by Gagner et al. (1), considering the improved patients outcomes, due to the reduced postoperative morbidity and postoperative pain, the faster recovery and the shorter length of hospital stay (2-5).

Currently LA is the "gold standard" treatment for the management of most adrenal surgical diseases, with an overall postoperative complication rate of about $10 \%$ (4-7). The growing experience with LA and the excellent results of this procedure have led several authors to propose it also for large and potentially malignant adrenal tumors (8-10). However, the experience is limited and no conclusive data are available yet (10-13).

In 1999, Piazza et al. (14) and Hubens et al. (15) reported the first cases of robot-assisted adrenalectomy (RA) using the ZEUS AESOP (Computer Motion, Inc., Santa Barbara, CA, USA). After the introduction of the da Vinci system (Intuitive Surgical, Sunnyvale, CA, USA), several series of robotic surgical procedures have been reported.

The widespread diffusion of robotic technology has led to the development and standardization of robot-assisted 
approach to adrenalectomy (16). RA has been proved to be feasible and safe in several Centers (16-24). The perceived advantages of RA can be considered the improved ergonomics, the stereoscopic vision, the tremor filtration, and greater range of motion within the operative field (25), potentially resulting in an ameliorated surgical dexterity and theoretically, maximizing the surgical efficiency of conventional LA. Indeed, it has been reported that RA may improve the performance of surgeons without extensive laparoscopic experience who wish to perform minimally invasive adrenalectomy (26).

Moreover, several variables, such as BMI $(17,20)$, previous abdominal surgery and tumor size (27) have been evaluated in different clinical settings, in order to figure out whether the RA approach is preferable to the conventional LA approach in selected complex patients and/or in selected complex adrenal masses. However, to date, no clear benefit from the use of the RA approach has been found (24), and cost increase still represents a major drawback correlated to RA $(24,27,28)$.

This review summarizes the current available data regarding RA including its operative outcomes, advantages and drawbacks in comparison with conventional LA, evaluating its cost-effectivity.

\section{Robotic adrenalectomy: operative and post- operative outcomes}

\section{Operative time}

It is acknowledged that the operative time of RA at the beginning of the experience is longer with respect to the conventional laparoscopic approach (28). First of all, the docking step can prolong the operative time by 15-40 minutes and can be as long as 1 hour at the start of the experience with RA $(18,25,29)$. Indeed, in some experiences it has been specifically addressed that docking time is responsible for the significant increase of operative time in RA (30,31). Moreover, several variables, as keeping the robotic platform in a dedicated operating room, completing the preparations of the robotic platform during the anaesthesia time and the familiarity of the surgical team with the robotic surgery, can significantly affect the operative time (28). On the other hand, extensive experience with laparoscopic surgery and previous exposure to robotic procedures are able to significantly reduce the learning curve of RA $(18,28)$. Several series identified in 20 cases the number of RA procedures needed to achieve similar outcomes to LA $(17-19,32,33)$. Brunaud et al., in a prospective series of $100 \mathrm{RA}$, reported a significant decrease of operative time after the first 50 cases (9) and observed no significant difference with the conventional laparoscopic counterpart after reaching the threshold of 20 cases (17). Similarly, different thresholds as 5 (34) and 10 cases (35) have been indicated by other authors for a significant decrease in the operative time in RA.

On the other hand, the application of robotic technology to more complex patients and tumors seems to be favourable in terms of operative time. Indeed, in a retrospective series comparing RA and LA (both with transabdominal and posterior retroperitoneoscopic approach) for adrenal tumors larger than $5 \mathrm{~cm}$, the application of robotic technology significantly shortened the operative time $(159.4 \pm 13.4$ vs. 187.2 $\pm 8.3 \mathrm{~min}$, respectively for RA and LA) (35). Accordingly, in a case-control study RA showed potential benefits compared to conventional LA, in particular on patients with nodules tumors $\geq 6 \mathrm{~cm}, \mathrm{BMI} \geq 30 \mathrm{~kg} / \mathrm{m}^{2}$, and with previous abdominal surgery (23).

In the case of bilateral adrenalectomy, RA had similar mean operative times with respect to conventional transabdominal lateral adrenalectomy (25). However, in a multicenter study comparing laparoscopic versus posterior retroperitoneoscopic versus robotic approach for synchronous bilateral adrenalectomy for Cushing's Syndrome, Raffaelli et al. (36), reported a significantly shorter operative time in the group of patients who underwent posterior retroperitoneoscopic adrenalectomy (PRA), since this approach eliminates the need to reposition the patient.

\section{Intra- and post-operative complications}

The majority of studies have demonstrated that RA is a safe technique with acceptable perioperative complications $(21,22,24,37)$. The average complication rate reported for RA is difficult to evaluate because of the lack of standardized definitions through the different studies. However, the average complication rate has been reported between 0 and $20 \%(22,25,37)$. Several meta-analyses concluded that patients who underwent RA may experience lower postoperative complications with respect to those who underwent conventional LA $(21,24)$. Nevertheless, a recent monocentric series of 303 unilateral RA showed a postoperative complication rate of about $10 \%$ (27), comparable to that of previous large studies evaluating conventional LA (4-7). Moreover, in the same study (27), four independent predictors for intraoperative and postoperative complications were identified: history of 
previous surgical procedures (upper GI and retroperitoneal), tumor size, patient's age, and conversion.

The average reported rate of capsular rupture during RA is about $3 \%(18,19,24,27)$, especially in patients with large adrenal masses $(18,19)$. The observed rate of capsular rupture is similar to previous large series evaluating conventional LA (4-6).

Similar to conventional LA, bleeding and local tumor adherence are the most frequent causes of conversion, which ranges from 0 to $11 \%(19,23,27,34)$. However, technical difficulties (limited visualization and poor port placement) have also been described (29). It can be argued that the conversion rate can be lowered as the learning curve is reached $(25,29)$.

Overall, morbidity and mortality rates are considered to be comparable between RA and conventional LA $(5,25)$. Post-operative complications associated to RA include haemorrhage, hematoma, wound infection, urinary tract infection, adjacent organ injury, ileus. In a recent metaanalysis by Economopoulos et al. (24) analysing 27 studies (13 comparatives and 14 non-comparative) RA and LA had similar intraoperative complications rate [odds ratio (OR): 1.20 ; 95\% CI, 0.33-4.38], postoperative complications (OR: 0.69; 95\% CI, 0.36-1.31), mortality (OR: $0.42 ; 95 \%$ CI, $0.07-2.72$ ), conversion to laparotomy (OR: $0.51 ; 95 \%$ CI, $0.21-1.23$ ) and conversion to laparotomy or laparoscopy (OR: 0.73; 95\% CI, 0.32-1.69).

Agrusa et al. (37) compared 379 patients who underwent RA vs. 419 patients who underwent LA. In the RA group a significantly inferior blood loss and a shorter hospital stay were observed. Accordingly, in their analysis of LA vs. RA, Economopoulos et al. (24) observed a shorter length of hospital stay in the robotic group, whereas they failed to find significant differences in terms of blood loss between the two groups.

According to the network meta-analysis by Heger et al. (38), comparing open versus minimally invasive adrenalectomy (both with conventional laparoscopic and robotic approach), the robotic approach, has the highest probability of being the treatment inducing the lowest intraoperative blood loss.

\section{Are there specific situations in which the robotic approach to adrenalectomy could be potentially superior to laparoscopic adrenalectomy?}

\section{Obesity}

The effect of obesity with a body mass index $\geq 30$ has been previously reported as a risk factor for complications in LA (39). However, more recently, it has been demonstrated that obesity does not impact either on the complication rate or on the prolonged length of hospital stay in LA, but it significantly affects the operative time $(40,41)$.

Similarly, the influence of obesity on operative outcomes of RA has led to discordant results with a relative scarcity of available data regarding this topic. Recently, Aksoy et al. (20) evaluated the effects of BMI $>30$ comparing 42 RA to 47 LA. Despite no significant differences in terms of operative outcomes were found between the two groups, the conversion rate was significantly higher in LA $(5.2 \%) v s$. RA $(0 \%)$. Therefore, the authors concluded that the application of robotic approach in a challenging category of patients, as the obese are, is able to overcome the technical difficulties in terms of exposure and dissection (20).

In a recent retrospective case-control study, Morelli et al. (23) compared $41 \mathrm{RA}$ to 41 conventional LA. The authors observed that robotic approach seemed to decrease mean operative time in the obese patient (BMI $>30 \mathrm{~kg} / \mathrm{m}^{2}$ ). Similarly, Brunaud et al. (18) confirmed the advantages offered by the robotic approach in obese patients without additional risk factors for procedural complexity.

In a recent retrospective comparative analysis (42) between obese (BMI >30) and non-obese (BMI <30) patients who underwent RA, no significant difference was found between the two groups in terms of operative outcomes. In conclusion, despite the paucity of data regarding perioperative outcomes of RA in obese patients, some evidence suggests that the robotic approach is safe in this challenging group of patients without a significant increase of postoperative morbidity rate.

\section{Large tumor size}

Large tumor size is generally associated with difficult dissection during LA, potentially leading to the risk of capsular effraction and impairment of oncologic outcome because of local recurrence (8-11). Currently, different threshold sizes have been considered to be "large" ranging from 5 to $10 \mathrm{~cm}$ with a general consensus of $6 \mathrm{~cm}(8-11)$.

Several studies showed that adrenalectomy is feasible with both laparoscopic and robotic approaches in patients with large adrenal tumors (25). From a theoretical point of view, if the interposition of the surgeon-computer interface can maximize the efficiency of the surgical procedure, RA would be more appropriate in this situation. Indeed, Morelli et al. (23) observed a shorter operative time in patients 
with tumor size $>6 \mathrm{~cm}$ who underwent RA. Similarly, other authors (29) observed a significantly decreased mean operative time in the group of patients with larger tumor size. As in conventional LA, also in RA the transabdominal route would be advisable in the subset of large adrenal lesions, because of the wider working space $(25,29)$. Thompson et al. (43) used the Swedish database including 659 adrenalectomies (250 were robotically assisted) and evaluated the role of the robotic approach in patients with large tumors, with the strategy of applying the robotic approach preferably in tumor with larger size.

In a recent revision of the National Cancer Database, Mishra et al. (44) compared the operative outcomes of 38 LA and 51 RA for adrenal malignancies with a median tumor size of $6.5 \mathrm{~cm}$. The study showed a significantly higher conversion rate in the LA group $(17.2 \%)$ with respect to the RA group (5.9\%).

Ball et al. reported that no prospective studies have been published on robotic approach in patients with large tumors including adrenocortical carcinoma (45). Furthermore, the results of retrospective studies comparing laparoscopic versus open approach for adrenocortical carcinoma were controversial. However, it could be argued that the oncologic outcome of ACC treated with endoscopic or robotic approach in referral centers is not inferior to that achieved with open adrenalectomy, when strict selection criteria and the principles of oncologic surgery are observed $(5,10)$.

\section{Cost-effectiveness of robotic adrenalectomy}

The increased costs of RA remain one of its main drawbacks. Brunaud et al. pointed out that the cost of RA was 2.3 times superior with respect to LA in their center (respectively, €4,155 vs. €1,799) (17).

This finding is similar to that of other authors' experiences. Indeed, Winter et al. reported median operative charges of $\$ 8,645$ for RA, $\$ 6,414$ for conventional LA, and \$3,666 for open adrenalectomy (46). However, median hospital charges did not differ significantly $(12,977 \$$, $11,599 \$$, and $\$ 14,600$ for RA, LA, and OA, respectively) thanks to shorter length of hospital stay of patients who had undergone minimally invasive surgery (46). Also, in the randomised controlled trial by Morino et al. (47) costs for the RA were higher compared to LA $(\$ 3,466$ vs. $\$ 2,737$, respectively). The charge difference was ascribed to the cost of the semi-disposable robotic instruments and to the longer operative times observed in the RA group. In addition, the cost difference did not consider the initial expense for the da Vinci system purchase (47).

Several studies have reported that patients who undergo adrenal surgery by low-volume surgeons are more likely to experience post-operative complications compared to their counterparts operated upon by high-volume surgeons (48). In addition, it has been observed that if low-volume surgeons' cases were managed by high volume surgeons, there would be savings of $8.1 \%$, since management costs were $\$ 14,263$ for high-volume surgeons and $\$ 16,437$ for the low-volume (49). These data, which refer to the LA, might be applied in the setting of RA, but controlled trials are needed.

On the other hand, increasing the number of robotic procedures performed per year is an effective depreciation modality of robotic system and consequently may bring a cost decrease (28). Indeed, Winter et al. calculated that if a centre performs over 500 robotic operations per year, then capital and maintenance costs for the robot would be $\$ 380$ per procedure (46). In accordance with these data, RA could become more sustainable in high-volume robotic surgery centers (24).

Since some studies have reported that robotic operative packs (comprehensive of instruments and of sterile drapes) may cost up to $900-950 \$$ per procedure, a limitation of the robotic instruments used during each procedure will probably bring an economic benefit $(47,50,51)$.

Similarly, Feng et al. (52) recently reported their strategies in order to reduce the cost correlated to RA with respect to LA. The calculated costs were $\$ 3,527$ for RA and $\$ 3,430$ for LA, with the average consumables fees being similar between the two groups $(\$ 1,106$ and $\$ 1,009$ respectively for RA and LA). The authors concluded that by limiting the number of robotic instruments and energy devices and utilising an experienced surgical team, the costs of RA can be kept similar to those of LA (52).

Overcosts due to the use of the robotic system could also be balanced by shortening the hospital stay, patients' referral increase, improved postoperative outcomes in more difficult patients (28).

However, to date, there are no available strong clinical data that could balance overcosts associated with the use of the robotic system (28).

The financial model of reimbursement has an important impact on the choice and feasibility of different techniques. But it is hard to compare these data considering the different systems adopted in various countries: this also explains, at least in part, the inhomogeneity of literature on the subject of costs of RA, and the need for more studies and data concerning its indications and benefits. 
Table 1 Comparative cost analysis among PRA, LTA and RA (Study period: January 2017-September 2019)

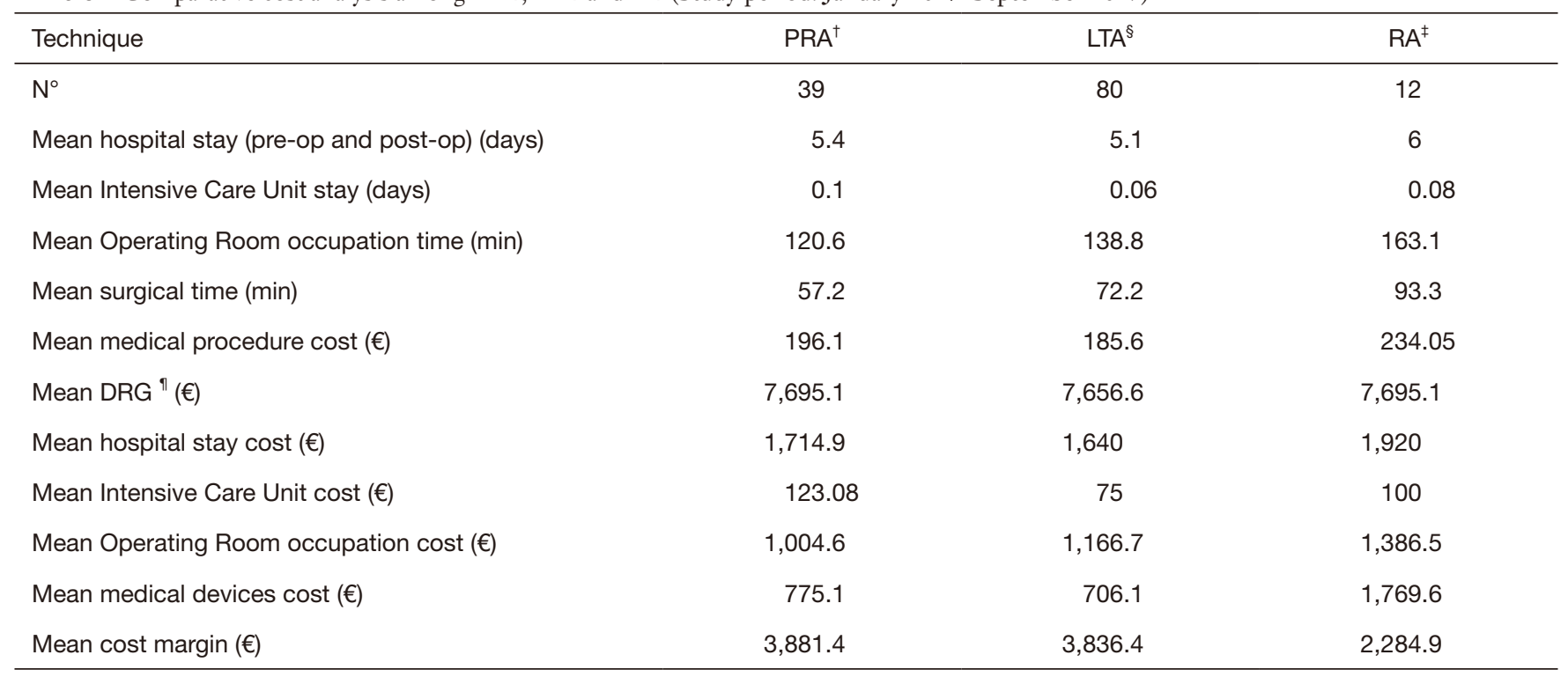

${ }^{\dagger}$, posterior retroperitoneoscopic adrenalectomy; ${ }^{\S}$, laparoscopic transabdominal adrenalectomy; ${ }^{\ddagger}$, robot-assisted adrenalectomy (transabdominal); ", diagnosis-related group. PRA, posterior retroperitoneoscopic adrenalectomy; LTA, laparoscopic transabdominal adrenalectomy; RA, robot-assisted adrenalectomy.

Although there are no available data on the reimbursement of adrenalectomy techniques based on the different providers, some authors have stated that flat reimbursement is not favourable in the use of new techniques, such as robotic surgeries, because they are often more expensive (28).

In this context, we evaluated the cost-effectiveness of RA with respect to other endoscopic approaches [laparoscopic lateral transabdominal adrenalectomy (LTA) and the PRA] in a public national health systems (NHS) in which inpatient care reimbursements are based on diagnosticrelated groups (DRG) and the reimbursement for robotic procedures is the same as that for the classical laparoscopic procedures.

Among a series of 731 adrenalectomies performed at a single third-care referral institution (91 RAs, 199 LTAs, 229 PRAs and 212 open adrenalectomies), 131 consecutive patients undergoing unilateral adrenalectomy between January 2017 and September 2019 were considered (39 PRA, 80 LTA and 12 RA). We performed a cost analysis including anesthesia and surgery professionals' fees, operating room costs, consumables materials and devices, hospital stay costs, prospectively collected for every single patient in the Institutional administrative database. Overall costs were subtracted to the DRGs reimbursement for adrenalectomy $(€ 7,695)$ in order to calculate the operating margins for PRA, LTA and RA. Mean operating room
(OR) occupation time was 120.6, 138.8, and 163.1 minutes, respectively for PRA, LTA and RA; while mean procedure time (skin to skin) was $57.2,72.2$, and 93.3 minutes, respectively for PRA, LTA and RA (Table 1). Mean postoperative stay was $4.0,3.9$, and 4.6 days, respectively for LTA, PRA, and RA. Median overall hospital costs per procedure were $3,813.71 €, 3,773.41 €$, and 5,410.10€, respectively for PRA, LTA and RA. Thanks to our analysis of the cost margin, we saw that it was positive for all the approaches: $50.4 \%, 50.1 \%$, and $29.7 \%$, respectively for PRA, LTA and RA (Figures 1-3). Specifically, the mean margin was 3,881, 3,836, and 2,285 euro for PRA, LTA, and RA, respectively (Table 1). In the subgroup analysis evaluating the impact of lesion size, the difference in marginality between RA and the other approaches decreased of about $20 \%$ for lesions $\geq 40 \mathrm{~mm}$.

Although in Italy the reimbursement is the same for laparoscopic and robotic surgeries (flat reimbursement), the cost margin for adrenalectomy was positive in our experience, even when the robot-assisted approach was used.

In our experience the increasing surgical load results in a proportional improvement of the cost margin. This effect is realised because of several factors, namely the significant decrease of the operative time, but also the effective employment of the operating room and of its resources.

The possibility to perform adrenal surgery with the three 


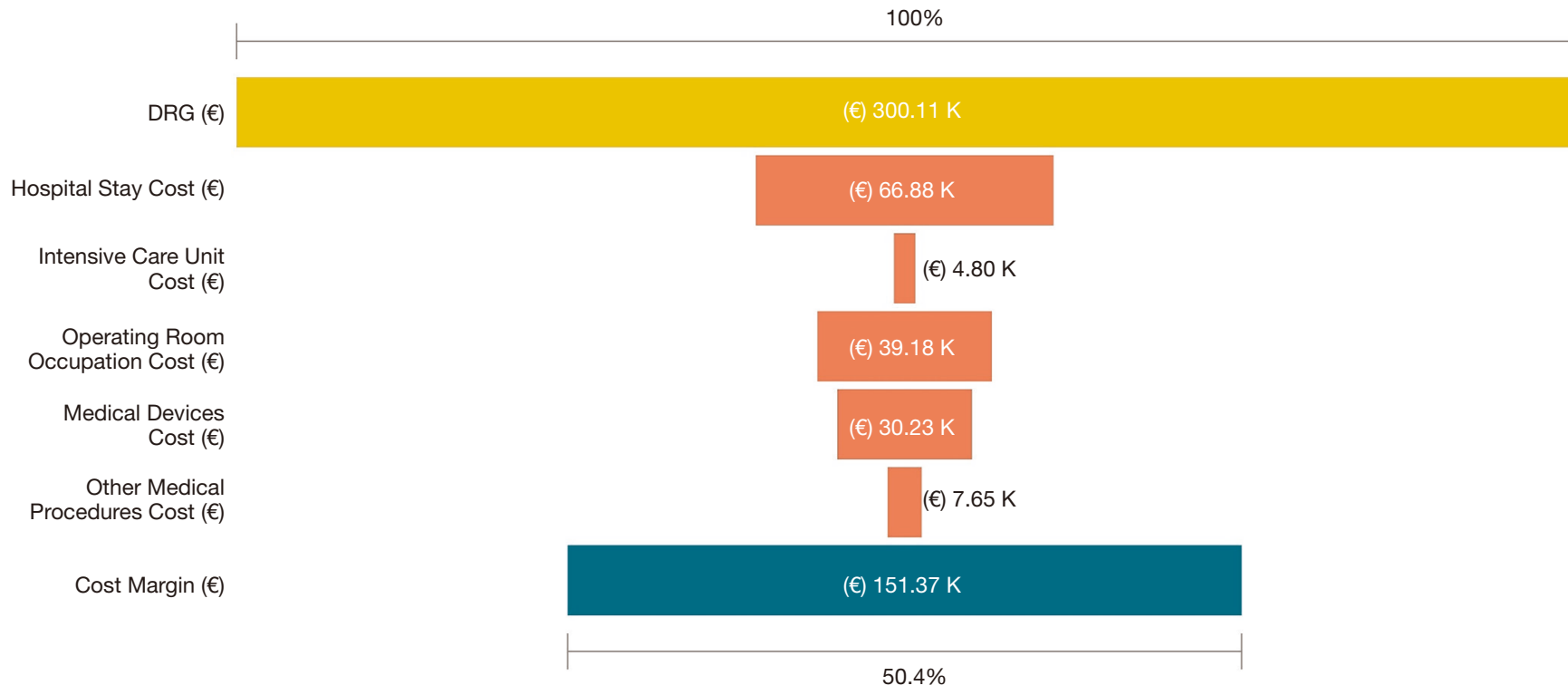

Figure 1 Overall costs and cost margin of posterior retroperitoneoscopic adrenalectomy (personal institutional experience).

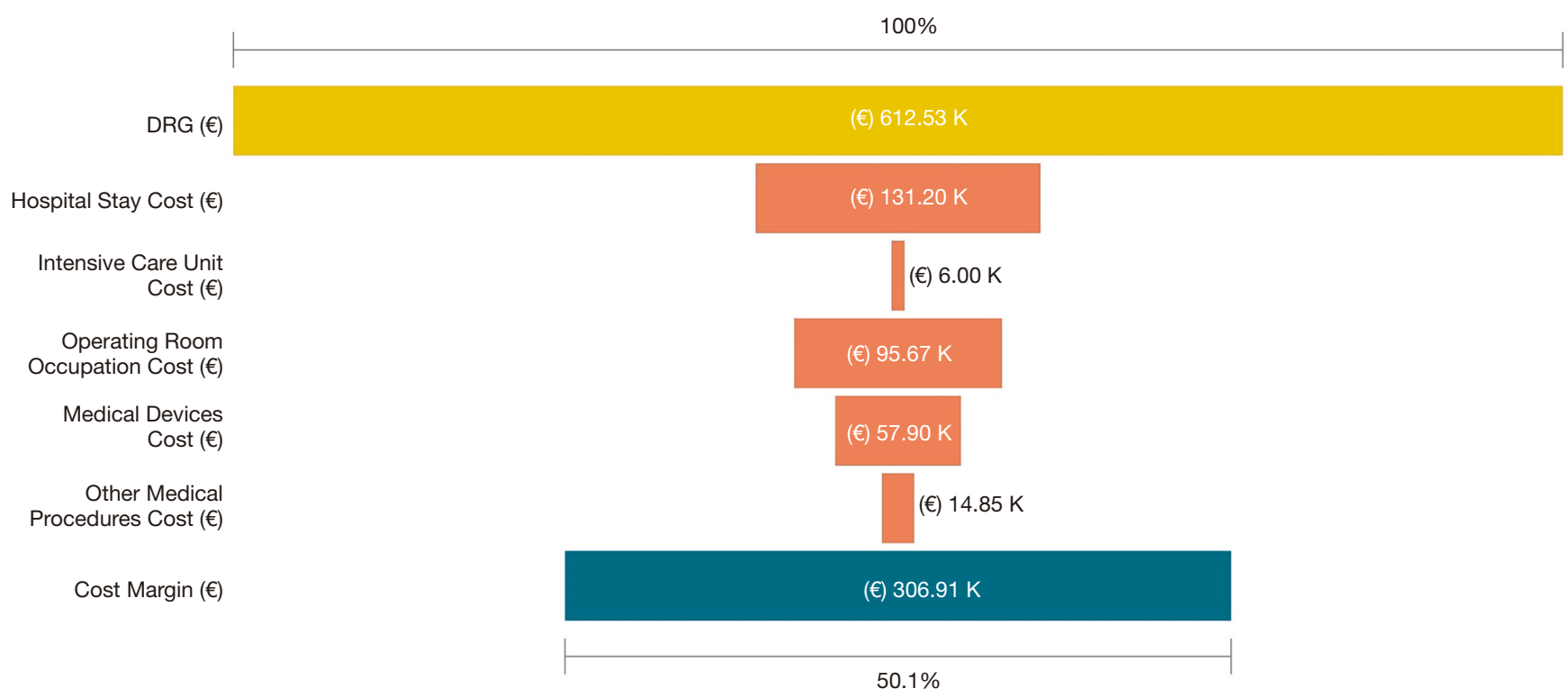

Figure 2 Overall costs and cost margin of lateral transabdominal adrenalectomy (institutional personal experience).

mentioned approaches offers an essential instrument to warrant the best possible equilibrium between economic sustainability and patient benefit.

\section{Conclusions}

Despite the higher cost, RA appears to be cost-effective and sustainable in a DRG-based reimbursement system in our experience. If reserved to larger and more challenging lesions, for which more benefits are expected by RA, the cost-effectiveness increases, and the differences with other techniques significantly reduce.

\section{Acknowledgments}

Funding: None. 


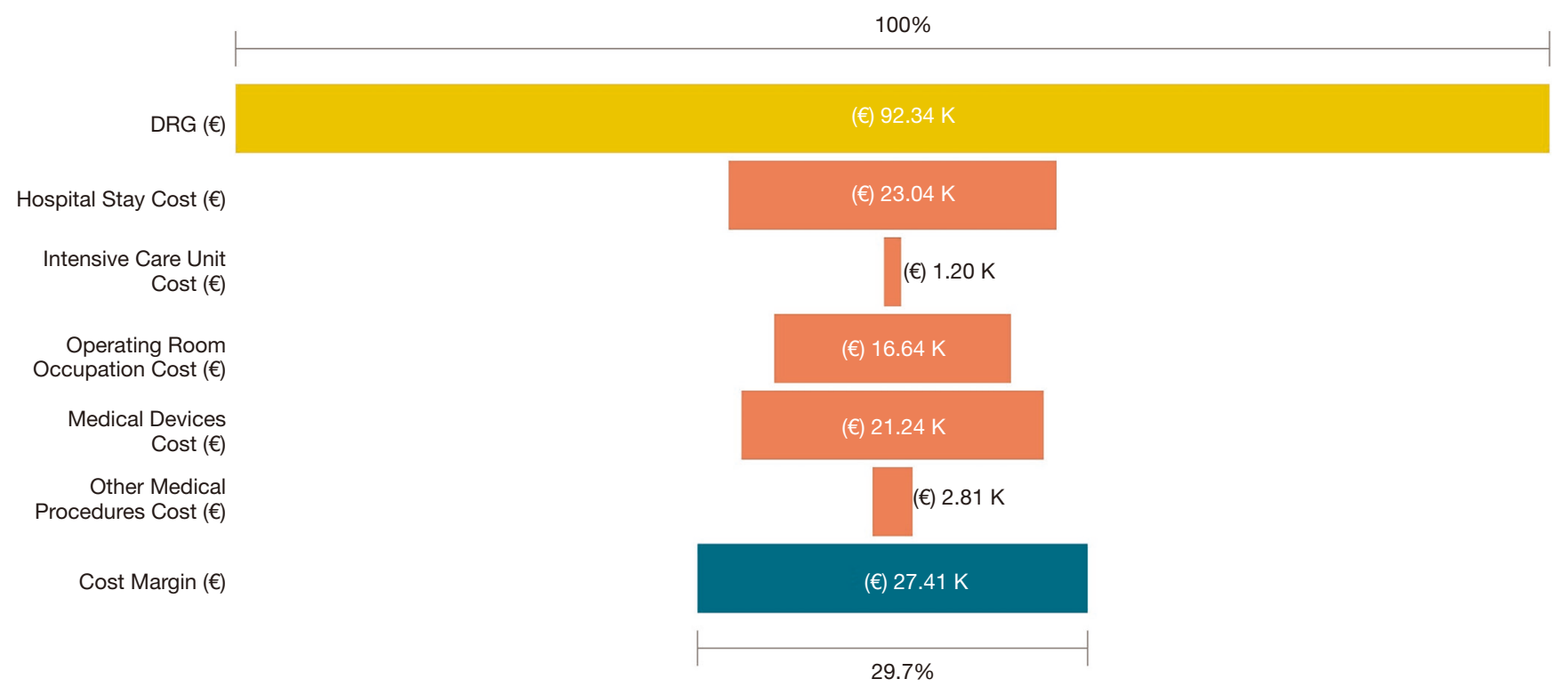

Figure 3 Overall costs and cost margin of robot-assisted adrenalectomy (personal institutional experience).

\section{Footnote}

Provenance and Peer Review: This article was commissioned by the Guest Editor (Özer Makay) for the series "Robotic Adrenalectomy" published in Gland Surgery. The article was sent for external peer review organized by the Guest Editor and the editorial office.

Conflicts of Interest: All authors have completed the ICMJE uniform disclosure form (available at http:// dx.doi.org/10.21037/gs.2020.03.44). The series "Robotic Adrenalectomy" was commissioned by the editorial office without any funding or sponsorship. The authors have no other conflicts of interest to declare.

Ethical Statement: The authors are accountable for all aspects of the work in ensuring that questions related to the accuracy or integrity of any part of the work are appropriately investigated and resolved.

Open Access Statement: This is an Open Access article distributed in accordance with the Creative Commons Attribution-NonCommercial-NoDerivs 4.0 International License (CC BY-NC-ND 4.0), which permits the noncommercial replication and distribution of the article with the strict proviso that no changes or edits are made and the original work is properly cited (including links to both the formal publication through the relevant DOI and the license).
See: https://creativecommons.org/licenses/by-nc-nd/4.0/.

\section{References}

1. Gagner M, Lacroix A, Bolté E. Laparoscopic adrenalectomy in Cushing's syndrome and pheochromocytoma. N Engl J Med 1992;327:1033.

2. Brunt LM, Doherty GM, Norton JA, et al. Laparoscopic adrenalectomy compared to open adrenalectomy for benign adrenal neoplasms. J Am Coll Surg 1996;183:1-10.

3. Assalia A, Gagner M. Laparoscopic adrenalectomy. Br J Surg 2004;91:1259-74.

4. Coste T, Caiazzo R, Torres F, et al. Laparoscopic adrenalectomy by transabdominal lateral approach: 20 years of experience. Surg Endosc 2017;31:2743-51.

5. Raffaelli M, De Crea C, Bellantone R. Laparoscopic adrenalectomy. Gland Surg 2019;8:S41-52.

6. Bittner JG, Gershuni VM, Matthews BD, et al. Risk factors affecting operative approach, conversion, and morbidity for adrenalectomy: a single-institution series of 402 patients. Surg Endosc 2013;27:2342-50.

7. Gaujoux S, Bonnet S, Leconte M, et al. Risk factors for conversion and complications after unilateral laparoscopic adrenalectomy. Br J Surg 2011;98:1392-9.

8. Kebebew E, Siperstein AE, Clark OH, et al. Results of laparoscopic adrenalectomy for suspected and unsuspected malignant adrenal neoplasms. Arch Surg 2002;137:948-51; discussion 952-3. 
9. Henry JF, Sebag F, Iacobone M, et al. Results of laparoscopic adrenalectomy for large and potentially malignant tumors. World J Surg 2002;26:1043-7.

10. Bellantone R, Lombardi CP, Raffaelli M. What is the appropriate role of minimally invasive vs. open surgery for small adrenocortical cancers? Curr Opin Oncol 2015;27:44-9.

11. Gaujoux S, Mihai R, joint working group of ESES and ENSAT. European Society of Endocrine Surgeons (ESES) and European Network for the Study of Adrenal Tumours (ENSAT) recommendations for the surgical management of adrenocortical carcinoma. Br J Surg 2017;104:358-76.

12. Stefanidis D, Goldfarb M, Kercher KW, et al. SAGES guidelines for minimally invasive treatment of adrenal pathology. Surg Endosc 2013;27:3960-80.

13. Carr AA, Wang TS. Minimally Invasive Adrenalectomy. Surg Oncol Clin N Am 2016;25:139-52.

14. Piazza L, Caragliano P, Scardilli M, et al. Laparoscopic robot-assisted right adrenalectomy and left ovariectomy (case reports). Chir Ital 1999;51:465-6.

15. Hubens G, Ysebaert D, Vaneerdeweg W, et al. Laparoscopic adrenalectomy with the aid of the AESOP 2000 robot. Acta Chir Belg 1999;99:125-7.

16. Desai MM, Gill IS, Kaouk JH, et al. Robotic-assisted laparoscopic adrenalectomy. Urology 2002;60:1104-7.

17. Brunaud L, Bresler L, Ayav A, et al. Robotic-assisted adrenalectomy: what advantages compared to lateral transperitoneal laparoscopic adrenalectomy? Am J Surg 2008;195:433-8.

18. Brunaud L, Ayav A, Zarnegar R, et al. Prospective evaluation of 100 robotic-assisted unilateral adrenalectomies. Surgery 2008;144:995-1001.

19. Giulianotti PC, Buchs NC, Addeo P, et al. Robot-assisted adrenalectomy: a technical option for the surgeon? Int J Med Robot 2011;7:27-32.

20. Aksoy E, Taskin H, Aliyev S, et al. Robotic versus laparoscopic adrenalectomy in obese patients. Surg Endosc 2013;27:1233-6.

21. Brandao LF, Autorino R, Laydner H, et al. Robotic versus laparoscopic adrenalectomy: a systematic review and metaanalysis. Eur Urol 2014;65:1154-61.

22. Tang K, Li H, Xia D, et al. Robot-assisted versus laparoscopic adrenalectomy: a systematic review and metaanalysis. J Laparoendosc Adv Surg Tech A 2015;25:187-95.

23. Morelli L, Tartaglia D, Bronzoni J, et al. Robotic assisted versus pure laparoscopic surgery of the adrenal glands: a case-control study comparing surgical techniques. Langenbecks Arch Surg 2016;401:999-1006.
24. Economopoulos KP, Mylonas K, Stamou AA, et al. Laparoscopic versus robotic adrenalectomy: a comprehensive metaanalysis. Int J Surg 2017;38:95-104.

25. Nomine-Criqui C, Germain A, Ayav A, et al. Robotassisted adrenalectomy: indications and drawbacks. Updates Surg 2017;69:127-33.

26. Talamini MA, Chapman S, Horgan S, et al. A prospective analysis of 211 robotic assisted surgical procedures. Surg Endosc 2003;17:1521-4.

27. Greilsamer T, Nomine-Criqui C, Thy M, et al. Roboticassisted unilateral adrenalectomy: risk factors for perioperative complications in 303 consecutive patients. Surg Endosc 2019;33:802-10.

28. Mihai R, Donatini G, Vidal O, et al. Volume-outcome correlation in adrenal surgery-an ESES consensus statement. Langenbecks Arch Surg 2019;404:795-806.

29. Teo XL, Lim SK. Robotic assisted adrenalectomy: Is it ready for prime time? Investig Clin Urol 2016;57:S130-46.

30. Hyams ES, Stifelman MD. The role of robotics for adrenal pathology. Curr Opin Urol 2009;19:89-96.

31. Pineda-Solís K, Medina-Franco H, Heslin MJ. Robotic versus laparoscopic adrenalectomy: a comparative study in a high-volume center. Surg Endosc 2013;27:599-602.

32. You JY, Lee HY, Son GS, et al. Comparison of robotic adrenalectomy with traditional laparoscopic adrenalectomy with a lateral transperitoneal approach: a single-surgeon experience. Int J Med Robot 2013;9:345-50.

33. Rosoff JS, Otto BJ, Del Pizzo JJ. The emerging role of robotics in adrenal surgery. Curr Urol Rep 2010;11:38-43.

34. D'Annibale A, Lucandri G, Monsellato I, et al. Robotic adrenalectomy: technical aspects, early results and learning curve. Int J Med Robot 2012;8:483-90.

35. Agcaoglu O, Aliyev S, Karabulut K, et al. Robotic versus laparoscopic resection of large adrenal tumors. Ann Surg Oncol 2012;19:2288-94.

36. Raffaelli M, Brunaud L, De Crea C, et al. Synchronous Bilateral Adrenalectomy for Cushing's Syndrome: Laparoscopic Versus Posterior Retroperitoneoscopic Versus Robotic Approach. World J Surg 2014;38:709-15.

37. Agrusa A, Romano G, Navarra G, et al. Innovation in endocrine surgery: robotic versus laparoscopic adrenalectomy. Meta-analysis and systematic literature review. Oncotarget 2017;8:102392-400.

38. Heger P, Probst P, Hüttner FJ, et al. Evaluation of open and minimally invasive adrenalectomy: a systematic review and network meta-analysis. World J Surg 2017;41:2746-57.

39. Kazaure HS, Roman SA, Sosa JA. Obesity is a predictor of 
morbidity in 1,629 patients who underwent adrenalectomy. World J Surg 2011;35:1287-95.

40. Economopoulos KP, Phitayakorn R, Lubitz CC, et al. Should specific patient clinical characteristics discourage adrenal surgeons from performing laparoscopic transperitoneal adrenalectomy? Surgery. 2016;159:240-8.

41. Chen Y, Scholten A, Chomsky-Higgins K, et al. Risk Factors Associated With Perioperative Complications and Prolonged Length of Stay After Laparoscopic Adrenalectomy. JAMA Surg 2018;153:1036-41.

42. Agcaoglu O, Akbas M, Ozdemir M, et al. The Impact of Body Mass Index on Perioperative Outcomes of Robotic Adrenalectomy: An Update. Surg Innov 2019;26:687-91.

43. Thompson LH, Nordenström E, Almquist M, et al. Risk factors for complications after adrenalectomy: results from a comprehensive national database. Langenbecks Arch Surg 2017;402:315-22.

44. Mishra K, Maurice MJ, Bukavina L, et al. Comparative Efficacy of Laparoscopic Versus Robotic Adrenalectomy for Adrenal Malignancy. Urology 2019;123:146-50.

45. Ball MW, Hemal AK, Allaf ME, et al. International Consultation on Urological Diseases and European Association of Urology International Consultation on

Cite this article as: De Crea C, Arcuri G, Pennestrì F, Paolantonio C, Bellantone R, Raffaelli M. Robotic adrenalectomy: evaluation of cost-effectiveness. Gland Surg 2020;9(3):831-839. doi: 10.21037/gs.2020.03.44
Minimally Invasive Surgery in Urology: laparoscopic and robotic adrenalectomy. BJU Int 2017;119:13-21.

46. Winter JM, Talamini MA, Stanfield CL, et al. Thirty robotic adrenalectomies: a single insitution's experience. Surg Endosc 2006;20:119-24.

47. Morino M, Benincà G, Giraudo G, et al. Robot-assisted vs. laparoscopic adrenalectomy: a prospective randomised controlled trial. Surg Endosc 2004;18:1742-6.

48. Park HS, Roman SA, Sosa JA. Outcomes from 3144 adrenalectomies in the United States: which matters more, surgeon volume or specialty? Arch Surg 2009;144:1060-7.

49. Al-Qurayshi Z, Robins R, Buell J, et al. Surgeon volume impact on outcomes and costs of adrenal surgeries. Eur J Surg Oncol 2016; 42:1483-90.

50. Barbash GI, Glied SA. New technology and health care costs - the case of robot-assisted surgery. N Engl J Med 2010;363:701-4.

51. Agcaoglu O, Aliyev S, Karabulut K, et al. Robotic vs. laparoscopic posterior retroperitoneal adrenalectomy. Arch Surg 2012;147:272-5.

52. Feng Z, Feng MP, Feng DP, et al. A cost-conscious approach to robotic adrenalectomy. J Robot Surg 2018;12:607-11. 